\title{
Dissolution of Ionizable Water-Insoluble Drugs: The Combined Effect of pH and Surfactant
}

\author{
JUNICHI JINNO, ${ }^{1 *}$, DOO-MAN OH, ${ }^{1}+$ JOHN R. CRISON, ${ }^{2}$ GORDON L. AMIDON ${ }^{1}$ \\ ${ }^{1}$ College of Pharmacy, The University of Michigan, Ann Arbor, Michigan 48109-1065 \\ 2 PORT Systems LLC, 540 Avis Drive, Ann Arbor, Michigan 48108
}

Received 17 June 1999; revised 11 November 1999; accepted 17 November 1999

\begin{abstract}
This study reports the results of the combined effect of $\mathrm{pH}$ and surfactant on the dissolution of piroxicam (PX), an ionizable water-insoluble drug in physiological $\mathrm{pH}$. The intrinsic dissolution rate $\left(J_{\text {total }}\right)$ of PX was measured in the $\mathrm{pH}$ range from 4.0 to 7.8 with $0 \%, 0.5 \%$, and $2.0 \%$ sodium lauryl sulfate (SLS) using the rotating disk apparatus. Solubility ( $c_{\text {total }}$ ) was also measured in the same $\mathrm{pH}$ and SLS concentration ranges. A simple additive model including an ionization ( $\left.\mathrm{PX} \leftrightarrow \mathrm{H}^{+}+\mathrm{PX}^{-}\right)$and two micellar solubilization equilibria $\left(\mathrm{PX}+\right.$ micelle $\leftrightarrow[\mathrm{PX}]_{\text {micelle }}, \mathrm{PX}^{-}+$micelle $\leftrightarrow$ $\left.\left[\mathrm{PX}^{-}\right]_{\text {micelle }}\right)$ were considered in the convective diffusion reaction model. $J_{\text {total }}$ and $c_{\text {total }}$ of PX increased with increasing $\mathrm{pH}$ and SLS concentration in an approximately additive manner. Nonlinear regression analysis showed that observed experimental data were well described with the proposed model $\left(r^{2}=0.86, P<0.001\right.$ for $J_{\text {total }}$ and $r^{2}=$ $0.98, P<0.001$ for $\left.c_{\text {total }}\right)$. The $\mathrm{p} K_{\mathrm{a}}$ value of $5.63 \pm 0.02$ estimated from $c_{\text {total }}$ agreed well with the reported value. The micellar solubilization equilibrium coefficient for the unionized drug was estimated to be $348 \pm 77 \mathrm{~L} / \mathrm{mol}$, while the value for the ionized drug was nearly equal to zero. The diffusion coefficients of the species $\mathrm{PX}, \mathrm{PX}^{-}$, and $[\mathrm{PX}]_{\mathrm{mi}^{-}}$ celle were estimated from the experimental results as $(0.93 \pm 0.35) \times 10^{-5},(1.4 \pm 0.30)$ $\times 10^{-5}$, and $(0.59 \pm 0.21) \times 10^{-5} \mathrm{~cm}^{2} / \mathrm{s}$, respectively. The total flux enhancement is less than the total solubility enhancement due to the smaller diffusion coefficients of the micellar species. This model may be useful in predicting the dissolution of an ionizable water insoluble drug as a function of $\mathrm{pH}$ and surfactant and for establishing in vitro-in vivo correlations, IVIVC, for maintaining bioequivalence of drug products. (C) 2000 WileyLiss, Inc. and the American Pharmaceutical Association J Pharm Sci 89: 268-274, 2000

Key words: piroxicam; solubility; dissolution; rotating disk method; $\mathrm{p} K_{\mathrm{a}}$; diffusivity
\end{abstract}

\section{INTRODUCTION}

A Biopharmaceutic Classification System (BCS) has been recently proposed for drug product bioequivalence requirements. Solubility and permeability, the key parameters in BCS, play impor-

Correspondence to: G. L. Amidon (E-mail: glamidon@ umich.edu)

*Current address: Otsuka Pharmaceutical Co., Ltd., 22418 Ebisuno Hiraishi Kawauchi-cho, Tokushima 771-0182, Japan

$\dagger$ Current address: Parke-Davis Pharmaceutical Co., Department of Pharmacokinetics, Dynamics and Metabolism, 2800 Plymouth Rd., Ann Arbor, MI 48105

Journal of Pharmaceutical Sciences, Vol. 89, 268-274 (2000)

(C) 2000 Wiley-Liss, Inc. and the American Pharmaceutical Association tant roles in the development of formulations and regulatory standards. Particularly for water insoluble drugs that have generally high membrane permeability (BCS Class II), dissolution and dose are the most critical factors affecting the rate and the extent of oral absorption. ${ }^{1}$ It is well known that dissolution is affected by the environmental changes in the gastrointestinal tract such as $\mathrm{pH}$, surfactant, ionic strength, buffer capacity, or viscosity. $^{2}$

The effect of $\mathrm{pH}$ and the effect of surfactant on the dissolution of drugs have been individually investigated by many researchers for the past several decades. Higuchi ${ }^{3}$ developed a one-dimensional diffusion layer theory describing the 
effect of surfactant on the dissolution of a solid. Gibaldi et al. ${ }^{4,5}$ examined the influence of polyoxyethylene (23) lauryl ether on the dissolution of benzoic acid and salicylic acid by the rotating disk and the static disk method. Singh et al. ${ }^{6}$ investigated the influence of micelle-drug solubilization on the dissolution rate for the benzocainepolysorbate 80 system under different hydrodynamic models. De Smidt et al. ${ }^{7-9}$ reported the effect of sodium lauryl sulfate on the dissolution of griseofulvin, a poorly soluble drug. On the other hand, Mooney et al. ${ }^{10,11}$ investigated the effect of $\mathrm{pH}$ on the solubility and dissolution of ionizable drugs based on a film model with total component material balances for reactive species, proposed by Olander. ${ }^{12}$ McNamara and Amidon ${ }^{13,14}$ developed a convective diffusion model that included the effects of ionization at the solid-liquid surface and irreversible reaction of the dissolved species in the hydrodynamic boundary layer. However, there is very little attention paid to the combined effect of $\mathrm{pH}$ and micellar solubilization.

The objective of this paper is to investigate the combined effect of $\mathrm{pH}$ and surfactant on the intrinsic dissolution rate of an ionizable water insoluble drug. Piroxicam (PX, Figure 1) was chosen as the model drug. The intrinsic dissolution and solubility of PX were measured in buffer solutions at various $\mathrm{pH}$ values and different concentrations of sodium lauryl sulfate (SLS) using the rotating disk dissolution method. A major question to be answered by these studies is whether additivity of $\mathrm{pH}$ and surfactant solubilization can account for the experimental results.

\section{THEORETICAL SECTION}

\section{Micelle Facilitated Dissolution Influenced by $\mathrm{pH}$}

\section{Model}

Both $\mathrm{pH}$ and surfactant often affect the dissolution of an ionizable water insoluble drug. Figure 2

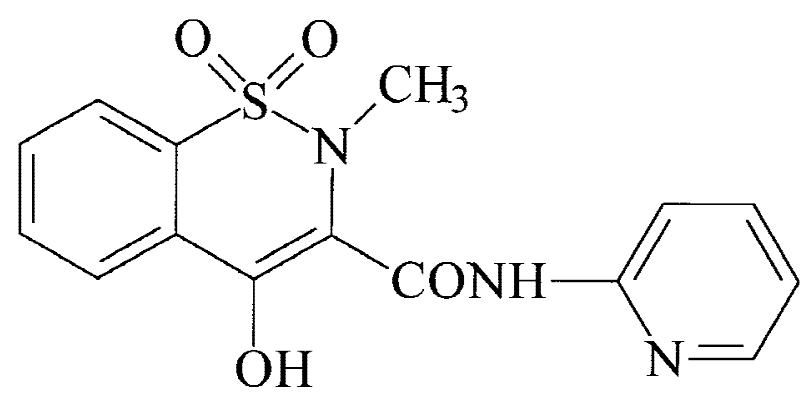

Figure 1. Structure of PX.
$[\mathrm{PX}]$ micelle<smiles>[Y][CH+]C=C</smiles>

micelle

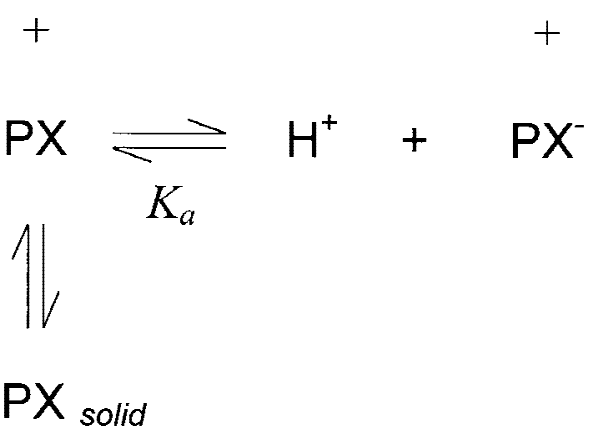

Figure 2. Equilibrium scheme of PX in surfactant solution.

illustrates a proposed model describing equilibria of PX in aqueous solution containing a surfactant. ${ }^{2}$ This scheme includes an ionization equilibrium and two solubilization equilibria. $\mathrm{PX}^{-}$, $[\mathrm{PX}]_{\text {micelle, }}$, and $\left[\mathrm{PX}^{-}\right]_{\text {micellar }}$ represent ionized drug, unionized drug in micelle, and ionized drug in the micelle, respectively. It is reported that PX can be ionized as a zwitterion which has two $\mathrm{p} K_{\mathrm{a}}$ values $\left(\mathrm{p} K_{\mathrm{a}_{1}}=1.86, \mathrm{p} K_{\mathrm{a}_{2}}=5.46\right.$ measured in DMSO-buffer 1:100). ${ }^{15}$ However, the $\mathrm{p} K_{\mathrm{a}_{1}}$ value is relatively low compared with the biological $\mathrm{pH}$ range of the small intestine. Therefore, PX was treated as a weak acid not an ampholyte in this paper. The equilibrium constant for the ionization is defined as follows:

$$
K_{\mathrm{a}}=\left(c_{\mathrm{PX}^{-}}\right)\left[\mathrm{H}^{+}\right] / c_{\mathrm{PX}}
$$

where $\left[\mathrm{H}^{+}\right]$is hydrogen ion concentration, and $c_{\mathrm{PX}}$ and $c_{\mathrm{PX}}{ }^{-}$are the concentrations of unionized and ionized drugs, respectively. The following equilibria between free solute and micelle solubilized solute are assumed ${ }^{16-19}$ :

$$
\begin{aligned}
& k^{*}=c_{[\mathrm{PX}] \text { micelle }} /\left\{\left(c_{\mathrm{PX}}\right)\left(c_{\mathrm{m}}\right)\right\} \\
& k^{* *}=c_{\left[\mathrm{PX}^{-}\right] \text {micelle }} /\left\{\left(c_{\mathrm{PX}^{-}}\right)\left(c_{\mathrm{m}}\right)\right\} \\
& c_{\mathrm{m}}=c_{\text {surfactant }}-\mathrm{cmc}
\end{aligned}
$$


where $k^{*}$ and $k^{* *}$ are the equilibrium constants for micellar solubilization of unionized and ionized species, $c_{\mathrm{m}}$ is the concentration of surfactant/ micelle which is equal to surfactant concentration $\left(c_{\text {surfactant }}\right)$ minus critical micelle concentration $\left(\mathrm{cmc}=0.008 \mathrm{M}\right.$ for SLS), ${ }^{17,20} c_{[\text {PX]micelle }}$ and $\left.c_{\left[\mathrm{PX}^{-}\right.}\right]_{\text {micelle }}$ are the concentrations of unionized and ionized drugs in the micelle, respectively.

\section{Total Solubility}

The combined effect of $\mathrm{pH}$ and surfactant on the solubility of weakly acidic and basic drugs was discussed by Rippie et al. ${ }^{16}$ The total solubility $\left(c_{\text {total }}\right)$ of a weak acid in surfactant solution can be expressed as a sum of the solubility values of each species:

$c_{\text {total }}=c_{\mathrm{PX}}+c_{\mathrm{PX}^{-}}+c_{[\mathrm{PX}] \text { micelle }}+c_{\left[\mathrm{PX}^{-}\right] \text {micelle }}$

Substituting $c_{\mathrm{PX}^{-}}, c_{[\mathrm{PX}] \text { micelle }}$, and $\left.c_{\left[\mathrm{PX}^{-}\right.}\right]_{\text {micelle }}$ in eq 5 using eqs 1,2 , and 3 gives eq 6 :

$$
\begin{aligned}
c_{\text {total }}= & \left\{1+K_{\mathrm{a}} /\left[\mathrm{H}^{+}\right]\right. \\
& \left.+\left(k^{*}+k^{* *} K_{\mathrm{a}} /\left[\mathrm{H}^{+}\right]\right) c_{\mathrm{m}}\right\} c_{\mathrm{PX}}
\end{aligned}
$$

\section{Dissolution}

The general equation describing the mass transport in a fluid is ${ }^{21}$

$$
\partial c_{i} / \partial t=D_{i} \nabla^{2} \mathrm{c}_{i}-\nu \nabla c_{i}+R_{i}
$$

where $D_{i}, \mathrm{c}_{i}$, and $R_{i}$ are the diffusion coefficient, the molar concentration, and the rate of production per volume of species $i$, $v$ is the fluid velocity, and $t$ is time. The terms on the right side of eq 7 represent the diffusive, convective, and reactive contributions to mass transfer, respectively. Assuming the instantaneous irreversible reactions at the solid-liquid surface, mass transfer in the rotating disk system at steady state can be simplified to

$$
D_{i} d^{2} c_{i} / d z^{2}-v_{z} d c_{i} / d z=0
$$

where $v_{z}$ is the axial velocity of fluid toward the disk. Levich ${ }^{22}$ solved the equation to derive the flux of the solute from the rotating disk as

$$
J=0.62 D_{i}^{2 / 3} v^{-1 / 6} \omega^{1 / 2} c_{i O}
$$

where $J$ is the flux, $v$ is the kinematic viscosity, $D_{i}$ is the diffusivity, $c_{i 0}$ is the concentration of species $i$ at the disk surface, and $\omega$ is the angular velocity of the disk. Equation 9 can be applied to the micelle-facilitated dissolution of an ionizable drug from the rotating disk to give

$$
J_{\text {total }}=0.62 D_{\text {eff }}^{2 / 3} v^{-1 / 6} \omega^{1 / 2} c_{\text {total }}
$$

where $J_{\text {total }}$ is the total flux of the drug and $D_{\text {eff }}$ is the effective diffusivity. The total dissolution rate $\left(J_{\text {total }}\right)$ is expressed as:

$$
\begin{aligned}
J_{\text {total }}= & J_{\mathrm{PX}}+J_{\mathrm{PX}^{-}}+J_{[\mathrm{PX}] \text { micelle }} \\
& +J_{\left[\mathrm{PX}^{-}\right] \text {micelle }}
\end{aligned}
$$

The dissolution rates for the each species are as follows:

$$
\begin{aligned}
J_{\mathrm{PX}} & =0.62 D_{\mathrm{PX}}{ }^{2 / 3} v^{-1 / 6} \omega^{1 / 2} c_{\mathrm{PX}} \\
J_{\mathrm{PX}^{-}} & =0.62 D_{\mathrm{PX}^{-}}{ }^{2 / 3} v^{-1 / 6} \omega^{1 / 2} c_{\mathrm{PX}^{-}} \\
J_{[\mathrm{PX}] \text { micelle }} & =0.62 D_{[\mathrm{PX}] \text { micelle }}{ }^{2 / 3} v^{-1 / 6} \omega^{1 / 2} c_{[\mathrm{PX}] \text { micelle }} \\
J_{\left[\mathrm{PX}^{-}\right] \text {micelle }} & =0.62 D_{\left[\mathrm{PX}^{-}\right] \text {micelle }}{ }^{2 / 3} v^{-1 / 6} \omega^{1 / 2} c_{\left[\mathrm{PX}^{-}\right] \text {micelle }}
\end{aligned}
$$

Substituting $J_{\mathrm{PX}}, J_{\mathrm{PX}^{-}}, J_{[\mathrm{PX}] \text { micelle }}$, and $\left.J_{[\mathrm{PX}}\right]$ micelle in eq 11 with eqs $12,13,14$, and 15 gives

$$
\begin{aligned}
J_{\text {total }}= & 0.62 v^{-1 / 6} \omega^{1 / 2} c_{\mathrm{PX}}\left(D_{\mathrm{PX}}{ }^{2 / 3}\right. \\
& +D_{\mathrm{PX}^{-}}{ }^{2 / 3} K_{\mathrm{a}} /\left[\mathrm{H}^{+}\right]+D_{[\mathrm{PX}] \text { micelle }}{ }^{2 / 3} k^{*} c_{\mathrm{m}} \\
& \left.+D_{\left[\mathrm{PX}^{-}\right] \text {micelle }}{ }^{2 / 3} k^{* *} K_{\mathrm{a}} /\left[\mathrm{H}^{+}\right] c_{\mathrm{m}}\right)
\end{aligned}
$$

for the total flux.

The experimental data will be evaluated for agreement with eq 6 for solubility and eq 16 for dissolution.

\section{EXPERIMENTAL SECTION}

\section{Materials and Data Analysis}

Piroxicam (PX) and sodium lauryl sulfate (SLS, $>99 \%$ purity) were purchased from Sigma Chemical Company (St. Louis, MO). Distilled, deionized, and filtered water was used for all experiments. A stainless steel rotating disk with a tablet radius of $0.55 \mathrm{~cm}$ was used for dissolution experiments. Model fitting and parameter estimations were performed with nonlinear regression analysis by SigmaPlot (SPSS Inc., Chicago, IL). The regression analysis for the dissolution data was weighted by reciprocal values of square of the standard deviation. 


\section{Dissolution Media}

McIlvaine buffers were prepared at $\mathrm{pH} 4.0,5.0$, $6.0,7.0$, and 7.8 by mixing appropriate volumes of $0.1 \mathrm{M}$ citric acid and $0.2 \mathrm{M}$ disodium phosphate solutions. SLS was dissolved with the buffers at the concentration of $0.5,1.0$, and $2.0 \mathrm{w} / \mathrm{v} \%$. The media were deaerated by stirring under vacuum prior to use.

\section{Dissolution Experiments}

The intrinsic dissolution rates of PX were determined using the rotating disk method. PX powder (200 mg) was compressed to form a circular compact in the rotating disk die at $1,000 \mathrm{lbs}$ for 10 min using a hydraulic press (Fred Carver, Inc., Summit, NJ). The die containing the compact was mounted onto a Plexiglass shaft attached to an overhead synchronous motor (Cole-Parmer Scientific, Niles, IL). The die was rotated at 50, 100, and $200 \mathrm{rpm}$. The rotational speed was calibrated with a digital tachometer (Cole-Parmer Scientific, Niles, IL). The single face of the compact was exposed to $150 \mathrm{~mL}$ of the dissolution medium in a jacketed beaker circulated with water heated at $37 \pm 1^{\circ} \mathrm{C}$ using a water bath circulator (Isotemp Constant Temperature Circulator Model 8000, Fisher Scientific, Pittsburgh, PA). The dissolution media was continuously circulated through a flow cell using a peristaltic pump (Masterflex, ColeParmer Scientific, IL) in $8 \mathrm{~mL} / \mathrm{min}$. UV absorbance at $254 \mathrm{~nm}$ was recorded at 1- or 5-min intervals using a UV spectrophotometer (PerkinElmer, Lambda 3B). Dissolved amounts of PX were maintained less than $10 \%$ of the solubility over the entire experiments to ensure sink condition.

\section{Solubility Experiments}

An excess amount of PX powder (50-200mg) was shaken in screw-capped vials containing $10 \mathrm{~mL}$ of buffers in an orbital shaker water bath (LABLINE Instruments, Inc., Melrose Park, IL) at $37^{\circ} \mathrm{C}$. At suitable time intervals $0.8-\mathrm{mL}$ samples were collected. The samples were filtered through $0.45 \mu \mathrm{m}$ membrane filters and diluted with the appropriate amount of buffer. PX concentration in the samples was assayed by the HPLC method described in United States Pharmacopeia XXII.

\section{RESULTS}

\section{Solubility-Time Profile}

The dissolved amount of PX versus time profile indicates a maximal value of solubility shown in

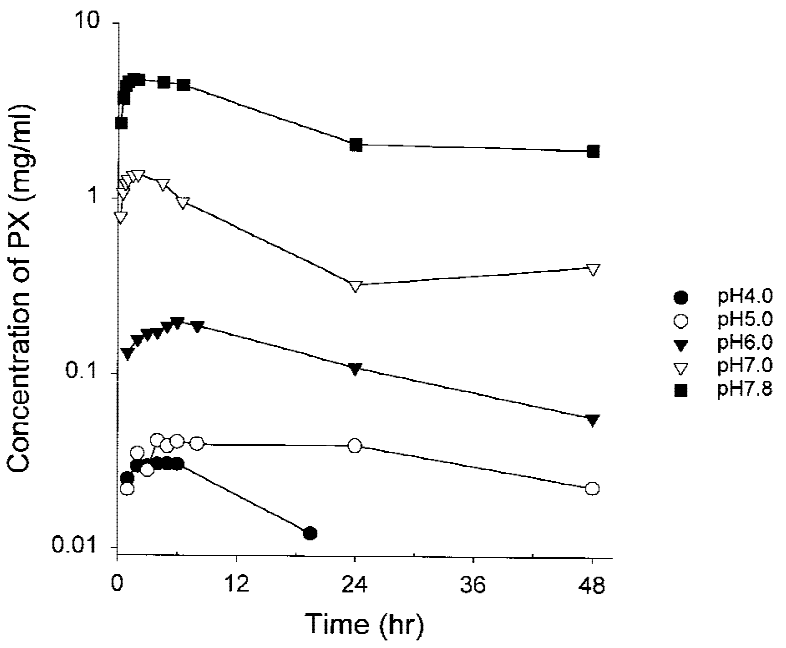

Figure 3. Solubility time profile of PX.

Figure 3. The maximal solubility was obtained after $8 \mathrm{~h}$ in the entire $\mathrm{pH}$ range except at $\mathrm{pH} 7.0$ and 7.8 without SLS where the peak occurred after $2 \mathrm{~h}$. The color of the crystals remaining on the bottom of the sample vial was white at the time when the solubility reached the maximum value. The color then gradually changed to yellow with decreasing solubility. This color change suggests a crystal form conversion from the original anhydrous form (white) to monohydrate (yellow). ${ }^{23,24}$ This type of phenomenon has been reported for theophylline, cholesterol, caffeine, glutethimide, and succinyl sulfathiazole. ${ }^{25}$ The maximal solubility values are most likely to be the driving force of dissolution and were 2-4 times higher than the values measured after 24 or $48 \mathrm{~h}$. It has been also reported that the anhydrous form has faster intestinal absorption than monohydrate after oral administration. ${ }^{26}$ The maximal solubility values were used for analysis in this report (Table I).

Table I. Maximal Solubility (mg/mL) of Piroxicam at Different $\mathrm{pH}$ and SLS Concentrations

\begin{tabular}{lllll}
\hline & \multicolumn{4}{c}{ SLS Concentration (w/v \%) } \\
\cline { 2 - 5 } $\mathrm{pH}$ & \multicolumn{1}{c}{0} & 0.5 & 1.0 & 2.0 \\
\hline 4.0 & 0.0320 & 0.178 & 0.265 & 0.497 \\
5.0 & 0.0396 & 0.188 & 0.334 & 0.531 \\
6.0 & 0.198 & 0.359 & 0.427 & 0.659 \\
7.0 & 1.37 & 1.45 & 1.62 & 1.98 \\
7.8 & 4.79 & 4.59 & 5.43 & 5.05 \\
\hline
\end{tabular}




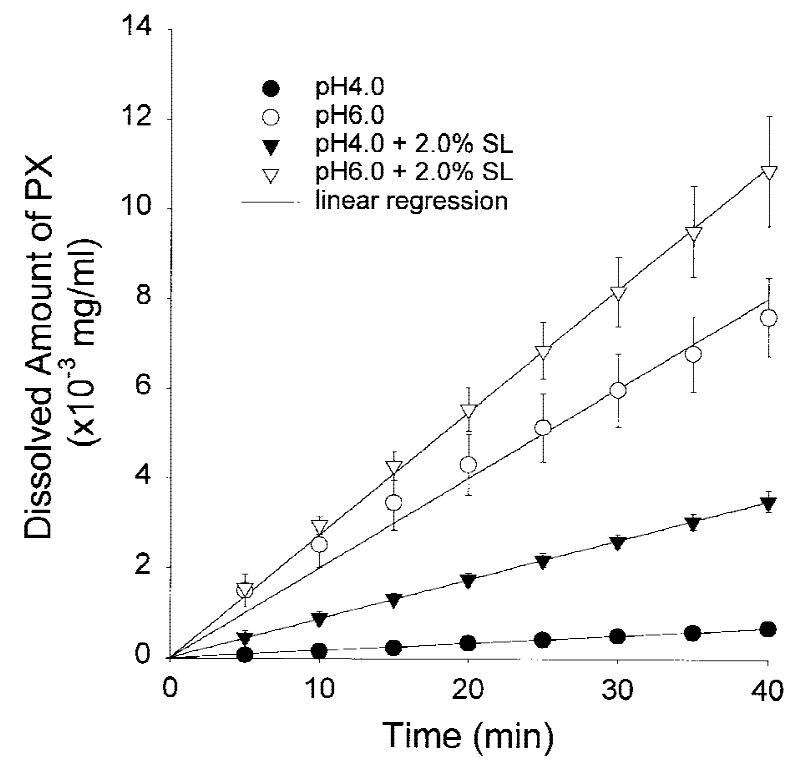

Figure 4. Dissolution curves of PX from the rotation disk at $50 \mathrm{rpm}$.

\section{Intrinsic Dissolution Rate}

Figure 4 shows typical results of the dissolution experiments. The intrinsic dissolution rates were calculated as a slope of the plot multiplied by the volume of media $(150 \mathrm{~mL})$ divided by the surface area of the compact $\left(0.950 \mathrm{~cm}^{2}\right)$ using linear regression assuming zero intercept. The obtained intrinsic dissolution rates are listed in Table II. The data are the average of triplicated values \pm the standard deviation while the average of duplicated values were presented for cases in the presence of SLS at $\mathrm{pH} 7.0$ and 7.8. Dissolution at pH 7.8 with $1.0 \%$ or $2.0 \%$ SLS was not measured due to rapid disintegration of the tablet.

\section{DISCUSSION}

\section{Nonlinear Regression Analysis of Solubility}

The total solubility increased with increasing $\mathrm{pH}$ and SLS concentration, as expected. The measured solubility values were fitted to eq 6 by nonlinear regression analysis. Figure 5 illustrates the fitted surface with the observed values as functions of $\mathrm{pH}$ and SLS concentration $\left(r^{2}=0.98\right.$, $P<0.001)$. The $\mathrm{p} K_{\mathrm{a}}$ value and the micellar solubilization equilibrium coefficients $\left(k^{*}\right.$ and $\left.k^{* *}\right)$ were estimated to be $5.63 \pm 0.02,348 \pm 77 \mathrm{~L} / \mathrm{mol}$, and $0.0 \pm 1.5 \mathrm{~L} / \mathrm{mol}$, respectively. The estimated $\mathrm{p} K_{\mathrm{a}}$ value agrees well with the reported $\mathrm{p} K_{\mathrm{a}_{2}}$ value of 5.46 determined in DMSO/water (1:100) by a spectrophotometric method. The low $k^{* *}$ value indicates that the micellar solubilization of ionized drug is negligible.

\section{Nonlinear Regression Analysis of Intrinsic Dissolution Rate}

Similar to the solubility, the dissolution rate also increased with increasing $\mathrm{pH}$ and SLS concentration. These enhancements in dissolution are well agreed with corresponding solubility enhancement. The dissolution data were fitted to eq 16 with the $\mathrm{p} K_{\mathrm{a}}$ and $k^{*}$ fixed at the estimated values from nonlinear regression analysis of the solubility data. The $k^{* *}$ value was assumed to be zero based on the analysis of solubility data. Figure 6 shows the result of the nonlinear regression analysis for the normalized dissolution rate $(\mathrm{J} /$ $\left.\omega^{1 / 2}\right)$ as functions of $\mathrm{pH}$ and SLS concentration $\left(r^{2}\right.$ $=0.86, P<0.02)$. The fitted surface is similar to that of the total solubility. In the $\mathrm{pH}$ range lower than its $\mathrm{p} K_{\mathrm{a}}$, a relatively large dissolution enhancement of up to 30 -fold, was observed by the addition of SLS. In the $\mathrm{pH}$ range higher than its

Table II. Intrinsic Dissolution Rate $\left(J / \omega^{1 / 2} ; \times 10^{4} \mathrm{mg} / \mathrm{cm}^{2} / \mathrm{s}^{1 / 2} / \mathrm{rad}^{1 / 2}\right)$ of Piroxicam at Different $\mathrm{pH}$ and SLS Concentrations

\begin{tabular}{lcccc}
\hline & \multicolumn{4}{c}{ SLS concentration (w/v \%) } \\
\cline { 2 - 5 } $\mathrm{pH}$ & 0 & 0.5 & 1.0 & 2.0 \\
\hline 4.0 & $0.201 \pm 0.009$ & $0.892 \pm 0.076$ & $1.30 \pm 0.15$ & $2.12 \pm 0.26$ \\
5.0 & $0.234 \pm 0.019$ & $0.837 \pm 0.115$ & $1.29 \pm 0.19$ & $2.04 \pm 0.25$ \\
6.0 & $1.01 \pm 0.04$ & $1.74 \pm 0.29$ & $2.95 \pm 0.16$ & $3.09 \pm 0.43$ \\
7.0 & $6.47 \pm 0.41$ & $10.8 \pm 1.1$ & $12.1 \pm 0.3$ & $11.8 \pm 0.3$ \\
7.8 & $19.8 \pm 1.3$ & $33.7 \pm 6.3$ & $\mathrm{a}$ & $\mathrm{a}$ \\
\hline
\end{tabular}

${ }^{\text {a }}$ Not measured due to disintegration of the disk. 


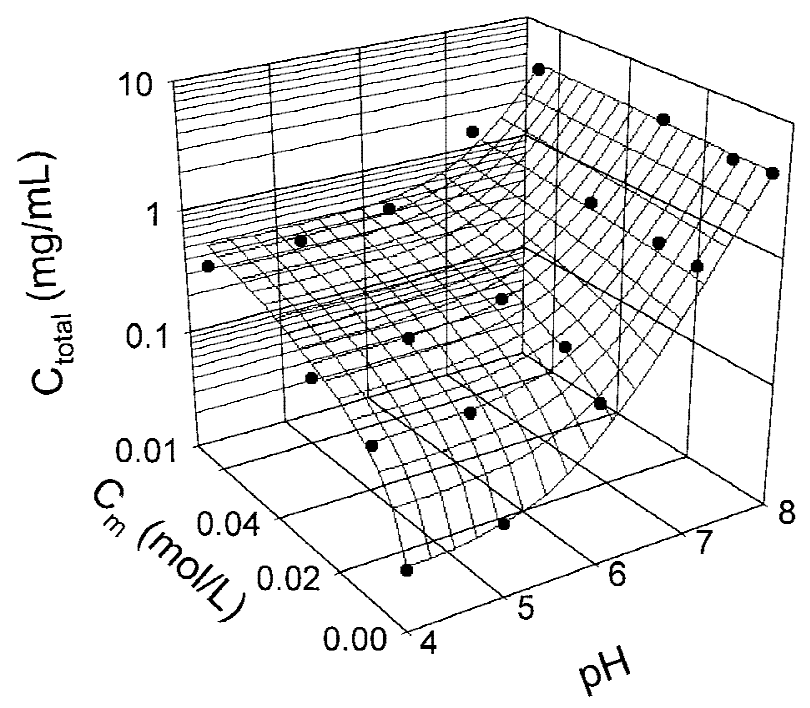

Figure 5. Total solubility of $\mathrm{PX}$ as a function of $\mathrm{pH}$ and surfactant.

$\mathrm{p} K_{\mathrm{a}}$; however, a relatively small enhancement of up to 3 -fold was observed. Since the $\mathrm{pH}$ in duodenum is around 5 and that in jejunum is 5-6 under fed state, the absorption of piroxicam can be increased by postprandial bile secretion. However, Ishizaki et al. ${ }^{27}$ reported that the extent of PX absorption in man was uninfluenced by food intake. This is probably due to potentially good absorption of PX due to its high jejunum permeability $\left(P_{\text {eff }}=(10.40 \pm 5.93) \times 10^{-4} \mathrm{~cm} / \mathrm{s} \text { in humans }\right)^{28}$ and relatively low dose number $\left(D_{\mathrm{o}}=11\right)$. The estimated diffusivity values for species $\mathrm{PX}, \mathrm{PX}^{-}$, and $[\mathrm{PX}]_{\text {micelle }}$ were $(0.93 \pm 0.35) \times 10^{-5},(1.42 \pm$ $0.30) \times 10^{-5}$, and $(0.59 \pm 0.21)-10^{-5} \mathrm{~cm}^{2} / \mathrm{s}$, respectively. The diffusivity value of PX agrees well with a theoretical value of $0.86 \times 10^{-5} \mathrm{~cm}^{2} / \mathrm{s}$ calculated from the estimated molal volume. ${ }^{29}$ The diffusivity of $[\mathrm{PX}]_{\text {micelle }}$ was 1.7 time lower than that of PX. This decrease in diffusivity is due to the higher molecular weight of $[\mathrm{PX}]_{\text {micelle }}$ compared to that of the free solute. ${ }^{5}$ However, this ratio is lower than the ratio of 9.0 observed for the carbamazepine-SLS system. ${ }^{18}$ Thus for the PXSLS system the enhancement in the dissolution rate is the result of the increase in total solubility due to the $\mathrm{pH}$ change and solubilization. These results suggest that the dissolution process in vivo, while more complicated due to the more complex and time-dependent environment, can be captured in vitro. However, when establishing an in vitro-in vivo correlation for a compound such as piroxicam, care must be taken when selecting the $\mathrm{pH}$ of the dissolution media and the hydrody-

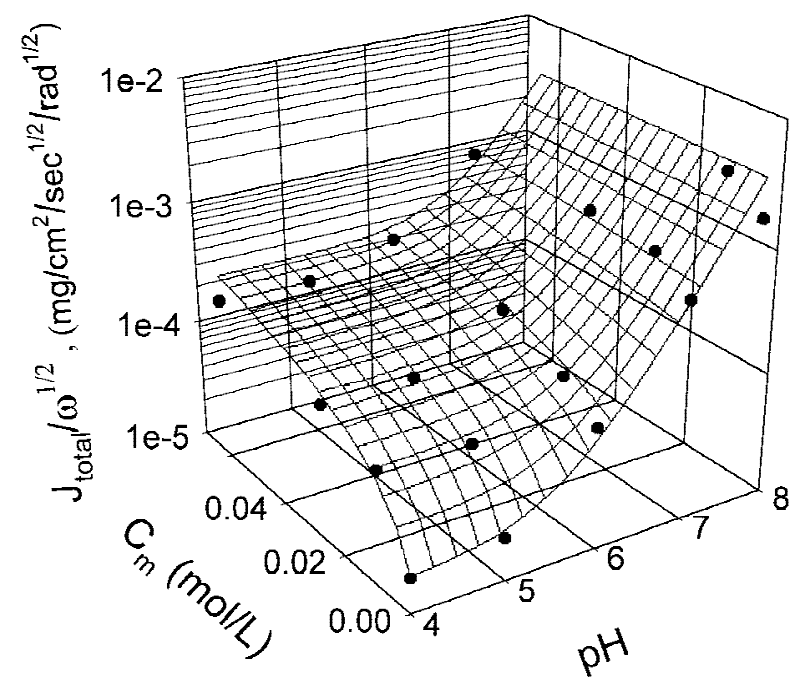

Figure 6. Dissolution rate as a function of $\mathrm{pH}$ and surfactant.

namics in the dissolution flask. For example, if the solubility of the drug in the dissolution media versus in vivo solubility is under-estimated, then the first derivative of the correlation between the fraction absorbed versus fraction dissolved will decrease with time. On the other hand, if the solubility of the drug in the dissolution media versus in vivo solubility is over-estimated, the first derivative of the correlation between the fraction absorbed versus fraction dissolved will increase with time. Thus, the time course of dissolution rates in vitro and in vivo will in general be different and some curvature in the IVIVC should be expected.

\section{CONCLUSION}

The dissolution rate and solubility of PX are well estimated by a simple additive model for the effect of $\mathrm{pH}$ and surfactant. The total solubility of $\mathrm{PX}$ is a sum of the values for the individual species $\mathrm{PX}, \mathrm{PX}^{-}$, and $[\mathrm{PX}]_{\text {micelle. The proposed model }}$ will be useful in predicting the dissolution and the solubility of an ionizable water-insoluble drug as functions of $\mathrm{pH}$ and surfactant. It also suggests that in vitro- in vivo correlations will in general show some curvature for BCS Class II drugs. ${ }^{1}$

\section{REFERENCES AND NOTES}

1. Amidon GL, Lennernas H, Shah VP, Crison JR. 1995. A theoretical basis for a biopharmaceutic 
drug classification: the correlation of in vitro drug product dissolution and in vivo bioavailability. Pharm Res 12:413-420.

2. Dressman JB, Amidon GL, Reppas C, Shah VP. 1998. Dissolution testing as a prognostic tool for oral drug absorption: immediate release dosage forms. Pharm Res 15:11-22.

3. Higuchi WI. 1964. Effects of Interacting Colloids on Transport Rates. J Pharm Sci 53:532-535.

4. Gibaldi M, Feldman S, Wynn R, Weiner ND. 1968. Dissolution rates in surfactant solutions under stirred and static conditions. J Pharm Sci 57:787791.

5. Gibaldi M, Feldman S, Weiner ND. 1970. Hydrodynamic and diffusional considerations in assessing the effects of surface active agents on the dissolution rate of drugs. Chem Pharm Bull 18:715723.

6. Singh P, Desai SJ, Flanagan DR, Simonelli AP, Higuchi WI. 1968. Mechanistic study of the influence of micelle solubilization and hydrodynamic factors on the dissolution rate of solid drugs. J Pharm Sci 57:959-965.

7. de Smidt JH, Offringa JC, Crommelin DJ. 1987. Dissolution kinetics of griseofulvin in sodium dodecylsulfate solutions. J Pharm Sci 76:711-714.

8. de Smidt JH, Offringa JC, Crommelin DJ. 1991. Dissolution rate of griseofulvin in bile salt solutions. J Pharm Sci 80:399-401.

9. de Smidt JH, Grit M, Crommelin DJ. 1994. Dissolution kinetics of griseofulvin in mixed micellar solutions. J Pharm Sci 83:1209-1212.

10. Mooney KG, Mintun MA, Himmelstein KJ, Stella VJ. 1981. Dissolution kinetics of carboxylic acids I: effect of $\mathrm{pH}$ under unbuffered conditions. J Pharm Sci 70:13-22.

11. Mooney KG, Mintun MA, Himmelstein KJ, Stella VJ. 1981. Dissolution kinetics of carboxylic acids II; effect of buffers. J Pharm Sci 70:22-32.

12. Olander DR. 1960. Simultaneous Mass Transfer and Equilibrium Chemical Reaction. A.I.Ch.E Journal 6:233-239.

13. McNamara DP, Amidon GL. 1986. Dissolution of acidic and basic compounds from the rotating disk: influence of convective diffusion and reaction. J Pharm Sci 75:858-868.

14. McNamara DP, Amidon GL. 1988. Reaction plane approach for estimating the effects of buffers on the disolution rate of acidic drugs. J Pharm Sci 77: 511-517.

15. Bernhard E, Zimmermann F. 1984. Contribution to the understanding of oxicam ionization constants. Arzneimittel-Forschung 34:647-648.

16. Rippie EG, Lamb DJ, Romig PW. 1964. Solubiliza- tion of Weakly Acidic and Basic Drugs by Aqueous Solutions of Polysorbate 80. J Pharm Sci 53:13461348.

17. Amidon GE, Higuchi WI, Ho NF. 1982. Theoretical and experimental studies of transport of micellesolubilized solutes. J Pharm Sci 71:77-84.

18. Crison JR, Shah VP, Skelly JP, Amidon GL. 1996. Drug dissolution into micellar solutions: development of a convective diffusion model and comparison to the film equilibrium model with application to surfactant-facilitated dissolution of carbamazepine. J Pharm Sci 85:1005-1011.

19. Crison JR, Weiner ND, Amidon GL. 1997. Dissolution media for in vitro testing of water-insoluble drugs: effect of surfactant purity and electrolyte on in vitro dissolution of carbamazepine in aqueous solutions of sodium lauryl sulfate. J Pharm Sci 86: 384-388.

20. Mukerjee P, Mysels KJ. 1971. Critical Micelle Concentrations of Aqueous Surfactant Systems, U.S. Dept. of Commerce: NSRDSNBS, pp 51.

21. Cussler EL. 1997. Diffusion: mass transfer in fluid systems, Cambridge University Press: New York, pp 65-67.

22. Levich VG. 1962. Physico-chemical hydrodynamics, Prentice-Hall: Englewood Cliffs, NJ; pp 39-72.

23. Bordner J. 1984. Piroxicam Monohydrate: a Zwitterionic Form, $\mathrm{C}_{15} \mathrm{H}_{13} \mathrm{~N}_{3} \mathrm{O}_{4} \mathrm{~S} . \mathrm{H}_{2} \mathrm{O}$. Acta Cryst C40:989-990.

24. Reck G, Dietz G, Laban G, Gunther W, Bannier G, Hohne E. 1988. X-ray studies on piroxicam modifications. Pharmazie 43:477-481.

25. Shefter E, Higuchi T. 1963. Dissolution behavior of crystalline solvated and nonsolvated forms of some pharmaceuticals. J Pharm Sci 52:781-791.

26. Kozjek F, Golic L, Zupet P, Palka E, Japelj M. et al. 1985. Physicochemical properties and bioavailability of two crystal forms of piroxicam. Acta Pharm Jugosl 35:275-281.

27. Ishizaki T, Nomura T, Abe T. 1979. Pharmacokinetics of piroxicam, a new nonsteroidal antiinflammatory agent, under fasting and postprandial states in man. Journal of Pharmacokin \& Biopharm 7:369-381.

28. Takamatsu N, Welage LS, Idkaidek NM, Liu DY, Lee PI, Hayashi Y, Rhie JK, Lennernas H, Barnett JL, Shah VP, Lesko L, Amidon GL. 1997. Human intestinal permeability of piroxicam, propranolol, phenylalanine, and PEG 400 determined by jejunal perfusion. Pharm Res 14:1127-1132.

29. Reid RC, Prausnitz JM, Sherwood TK. 1977. The properties of gases and liquids, McGraw Hill Book Co: New York; pp 57-59, 567-582. 